\title{
LAS ÁREAS RURALES DE MONTAÑA EN LA ESPAÑA DEL SIGLO XVIII: EL CASO DE LAS SIERRAS DEL SUR DE LA RIOJA
}

\author{
JOSÉ RAMÓN MORENO FERNÁNDEZ * \\ Universidad de Zaragoza
}

\begin{abstract}
RESUMEN
Concebidas como un tipo especial de economias preindustriales, las economías de montaña presentaban peculiaridades muy notables. Desde este supuesto, se discuten tres ideas tradicionales: que la economía rural en el Antiguo Régimen se agotaba en lo agrario; que la economía preindustrial se movía al margen o a espaldas del mercado, y que la montaña era un entorno marginal. Para ello, el trabajo se basa en el análisis de la economía de las sierras de La Rioja a mediados del siglo XVII, con especial énfasis en la pluriactividad, el papel del mercado, los enfoques basados en las economías familiares y la importancia de los marcos institucionales comunales.
\end{abstract}

\section{ABSTRACT}

Conceived as special types of preindustrial economies, the economies of the mountain areas had many distinctive features. Based on this assumption, three traditional ideas are discussed: that the rural economy in the Ancien Regime was limited to agrarian activities; that the pre-industrial economy functioned independently of, or outside the market and that the mountain areas were a marginal environment. For this reason, this work is based on the analy. sis of the sierras of La Rioja in the middle of the 18th Century, with special emphasis on multiple occupation (pluriactivity), the role of the market, approaches based on family economies and the importance of communal institutional frameworks.

* Agradezco a Iñaki Iriarte, Fernando Arbués y Santiago López su lectura y sus acertados comentarios sobre versiones anteriores del trabajo. Una redacción preliminar se presentó en el Seminario de Cuenca, donde se pudo beneficiar de múltiples sugerencias, algunas de las cuales se han incorporado al texto final. Naturalmente, los errores que puedan subsistir son de mi exclusiva responsabilidad. 


\section{INTRODUCCIÓN}

Este trabajo pretende aportar argumentos útiles para enriquecer la interpretación tradicional del medio rural preindustrial. En él se discuten la idea de que la economía rural en el Antiguo Régimen se agotaba en lo agrario - un axioma entendido a menudo como simple agricultura de subsistencia-, la suposición de que la economía preindustrial se movía al margen o a espaldas del mercado, y la imagen de la montaña como un entorno marginal. Frente a estos planteamientos, desde la historia agraria se ha desarrollado en los últimos años un serio trabajo para renovar nuestra visión del medio rural precapitalista. Entre las novedades más significativas se encuentra la percepción de que muchas áreas rurales mostraban, en el siglo Xxx y también en los siglos precedentes, un gran dinamismo económico a través de su vinculación con los mercados y de la presencia de prácticas pluriactivas en la mayor parte de los hogares. Estos rasgos han pasado a formar parte incluso de la definición de campesinado y economía campesina ${ }^{1}$.

En concreto, hay amplias comarcas que fueron incapaces de producir los alimentos necesarios para satisfacer las necesidades de su población. Eran, entre otras, las áreas de montaña. De entrada, la montaña no era sólo un sistema agrario. La falta de tierra de cultivo y la escasez alimentaria obligaban a practicar actividades no agrícolas que proporcionaran ingresos para financiar la importación de granos. Así, se crearon originales fórmulas sociales y mercantiles aptas para afrontar las necesidades y transformadoras de los contextos institucionales tradicionales. En lo económico, unas comarcas se especializaron en la ganadería; otras, en la transformación de los recursos que tenían a mano — carbón vegetal, lana, madera, energía hidráulica-; otras, en el comercio - trajineros o arrieros-; otras, se limitaban a expulsar la población sobrante, y, casi todas, por último, combinaban todas estas opciones dando lugar a patrones económicos complejos y muy dinámicos en contraste con algunas áreas de llanura en las que no había tal diversidad. La montaña se debe definir, por tanto, como un sistema abierto, forzado a intercambiar mercancías con otras áreas, próximas o lejanas ${ }^{2}$.

' Domínguez Martín (1992) y (1993). Hasta los trabajos de este autor, tanto la pluriactividad como el papel del mercado estaban ausentes de los análisis sobre el medio rural español. (1990).

${ }^{2}$ Una justificación teórica de este planteamiento, desde la geografía, en García Ruiz 
Con este trasfondo, las siguientes páginas se apoyan en el análisis de la montaña riojana, pensada como laboratorio de pruebas: analizando un tipo de economías rurales, las que tenían mayores dificultades agrícolas, se trata de revisar los pilares básicos del modelo económico existente a mediados del siglo xvm, es decir, en un momento en el que se le puede atribuir un elevado grado de madurez, tras una larga trayectoria. En la siguiente sección se detallan las principales novedades de esta aproximación. A continuación se entrelazan con las bases económicas, sociales e institucionales de las sierras riojanas. Por último, en las conclusiones, se hace hincapié en las consecuencias metodológicas y teóricas más relevantes.

\section{UNA PROPUESTA PARA EL ANÁLISIS DE LA MONTAÑA PREINDUSTRIAL}

La definición de cualquier modelo económico preindustrial, del que la montaña es un caso particular por sus condiciones ecológicas, obliga a estudiar las condiciones ambientales, los sistemas de propiedad - no sólo de la propiedad agrícola, sino del conjunto de los medios de producción-y las estructuras sociales resultantes. Así han procedido los análisis tradicionales. Pero, a partir de ahí, también se debe recurrir a cuatro pilares teóricos que comienzan ya a considerarse como indispensables en los estudios empíricos. Se trata, primero, de entender la economía rural como una economía básicamente familiar; segundo, de hacer justicia a la pluriactividad rural; tercero, de reconocer el papel desempeñado por el mercado en una sociedad vinculada a importantes flujos mercantiles; $y$, cuarto, de identificar, en el marco institucional, cómo se organizaban los sistemas productivos y distributivos ${ }^{3}$. Ninguno de estos elementos era exclusivo de la montaña, aunque la pluriactividad y el mercado se presentaban en ella con mayor intensidad.

La economía familiar es el componente teórico fundamental para entender las estrategias campesinas de relación con el mercado y con las oportunidades del medio natural. Es evidente que la familia campesina es el núcleo de decisión y la unidad básica de producción, consumo y reproducción, así como el núcleo fundamental de las solidaridades humanas. Ahora bien, esta institución está todavía hoy sometida a malos entendidos.

${ }^{3}$ Aquí se plantea como punto de partida lo que, en realidad, ha sido antes el punto de llegada de una investigación empírica minuciosa; para su desarrollo detallado véase Moreno Fernández (1999). 
Las causas principales han sido su idealización como una institución rígida y una deficiente comprensión de las relaciones internas en el seno familiar. Se tiende a contemplar la familia como un bloque de intereses compartidos de modo estable por todos sus miembros. Ahora bien, dependiendo de la fase vital del hogar campesino y de los cambios en la economía de su entorno, las opciones se limitan o se amplían y trastornan los intereses familiares. Además, abundan las razones para pensar la familia como una institución jerarquizada y desigual, sometida a tensiones internas y dirigida de forma no democrática. Sólo así es posible entender la división por género y edad del trabajo y el hecho de que las tareas más exigentes en sacrificios personales -ingratas, mal pagadas, poco especializadas y reiterativastiendan a recaer sobre los más débiles: mujeres y niños ${ }^{4}$.

En segundo lugar, hay que contar con la notable presencia económica y social de la diversidad de actividades, tanto en el seno de las familias como en la estructura económica serrana. Este fenómeno, que se ha dado en llamar pluriactividad, se encarnaba en las montañas en una presencia muy visible de actividades de transformación y de transporte ${ }^{5}$. La pluriactividad era resultado tanto del entorno natural como del institucional. La base económica sobre la que actuaban los grupos sociales era una consecuencia del marco ecológico, pero también del estado del mercado. El medio natural proporcionaba oportunidades y trazaba los límites. Éstos y aquéllas se resolvían de modos diversos en función del margen de maniobra de cada grupo social, lo cual estaba muy vinculado a la cercanía y al control de los instrumentos del poder local. Se trataba, en fin, de un problema histórico, que se resolvía de forma variable a partir de un conjunto de determinantes múltiples ${ }^{6}$.

En tercer lugar, el mercado, aun en el siglo xvin, era un medio capaz de asignar factores y de definir vías de especialización, incluso con las limitaciones impuestas desde el marco institucional. Y esto vale menos

${ }^{4}$ Los problemas de género ya empiezan a ser asumidos por la historiografia desde que la perspectiva familiar se ha encontrado con la economía e historia feministas. La división generacional no ha corrido igual suerte, aunque se pueden aplicar a ésta algunos avances teóricos de aquellos trabajos.

5 Mayaud (1988), Cazzola (1987) y Fontaine (1991).

6 Garrier, Goujon y Rinaudo (1988), p. 234, distinguen dos formas de pluriactividad: una cerrada, confinada a un espacio restringido y dirigida a mantener la «autarquía comu. nitaria del grupo», y otra abierta, que produce para circuitos mercantiles. Ahora bien, lo común era una pluriactividad que emanaba de las raíces mismas de la economía rural y que trascendía la estrechez de la noción autarquía: en el fondo, todas las actividades múltiples encuentran expedito el camino a partir de la propia estacionalidad del trabajo agrícola y de las oportunidades aportadas por el comunal. 
para el mercado de productos que para el mercado de trabajo o el de medios de producción. Se trataba de un mercado un tanto peculiar, en el que las imperfecciones y los fallos formaban parte de su naturaleza en un grado notable, cuestión que no le resta un ápice de importancia, aunque sí altera el modo en el que hay que afrontar el estudio de las propiedades de esta institución a partir de las trabas que, frenando su influencia, no dejaban de hacerla posible.

Finalmente, el cuarto argumento teórico que sirve de nervio al trabajo es el marco institucional. Un marco sobre todo comunal -me refiero a su contenido patrimonial, pero también, en una perspectiva más general, a la capacidad de regulación comunitaria tanto de los negocios comunes como de las vidas privadas-- Cualquier decisión institucional dependía del balance extraído tras un análisis implícito de la dotación ambiental del territorio y de las presiones sociales y económicas. En el fondo, se trataba de hacer un resumen comprensivo de las anteriores condiciones: según las posibilidades naturales, el desarrollo del mercado y las limitaciones de la estructura social, las familias tenían a su disposición un abanico más o menos amplio de oportunidades y lo explotaban con enfoques pluriactivos. El marco institucional tenía esto en cuenta, junto a las preocupaciones de los más poderosos y, en aquellos momentos en los que se había logrado un cierto equilibrio de intereses, procuraba darle continuidad arbitrando mecanismos dirigidos a su mantenimiento. Esto, en la medida en que dependía de la evolución del mercado y de variables coyunturales, daba lugar a una gran variabilidad en el tiempo y en el espacio, la cual sólo se podía traducir en acuerdos efectivos mediante la autorregulación flexible: es decir, mediante la capacidad que las fuerzas sociales tenían para decidir su propio destino con arreglo a sus propias condiciones, lo que vendría a ser equivalente a un cierto modo de salvarse en común ${ }^{7}$. Como consecuencia, el principal objetivo - no tanto deliberado, sino más bien un efecto del contrapeso de intereses opuestos-, se dirigía a promover la reproducción de las condiciones existentes. El encuadre institucional, en este contexto, es el elemento clave para distinguir la vitalidad de los distintos modelos vigentes entre los sistemas agrarios del siglo XVIII.

${ }^{7}$ He definido con más precisión lo que entiendo por autorregulación en Moreno Fernández (1998). 


\section{LA MONTAÑA RIOJANA A MEDIADOS DEL SIGLO XVIII}

En las sierras riojanas se había formado un sistema económico que no resultaba del todo excepcional en las décadas centrales del siglo xviI ${ }^{8}$. Aunque tal vez en La Rioja el dinamismo era superior al que encontramos en otras áreas, aquí, como en otros lugares inapropiados para la agricultura, se desarrollaron el subsector pecuario y actividades de transformación que definían una economía compleja y dinámica ${ }^{9}$. En principio, la pobreza agraria tenía tres salidas: la expulsión de los excedentes poblacionales, la búsqueda de alternativas económicas al margen de lo agrario, o una original combinación de éstas ${ }^{10}$. Siguiendo la tercera opción, la estructura económica de las sierras descansaba sobre la ganadería ovina trashumante, el textil lanero y el comercio pañero, actividades que implicaban desplazamientos estacionales de población, y que estaban vinculadas entre sí, conectadas a los mercados, acopladas a las acusadas diferencias sociales, potenciadas por el entramado comunal y complementadas con la insuficiente agricultura ${ }^{11}$.

${ }^{3}$ Es dificil, sin embargo, afirmar con rotundidad el grado de excepcionalidad del caso riojano, porque los análisis tradicionales de la montaña se han hecho con puntos de partida diferentes, con una mayor atención a lo agrícola y sin reconocer el papel de los mercados y de la pluriactividad.

9 En toda esta sección se va a trabajar con los datos del Catastro de Ensenada en todos sus niveles de elaboración - estados generales, respuestas generales, libros mayores de lo raíz, libros de lo personal y memoriales-y con muestras de distinta amplitud escogidas por la calidad de su información para compensar la heterogeneidad intrínseca de la fuente. Casi todas las afirmaciones que figuran en los próximos párrafos son resultado de un laborioso proceso de elaboración que no cabe en veinte páginas y que se ha justificado detalladamente en Moreno Fernández (1999).

${ }^{10}$ Normalmente se establecían movimientos estacionales siguiendo canales abiertos por el traslado del ganado, por la demanda de trabajo en otras comarcas, o por oportunidades comerciales. Ver Ortega Valcárcel (1974), pp. 218-219, Lanza García (1988), y Sarasúa (1994). Sobre las alternativas económicas a la agricultura se pueden consultar los antecedentes más clásicos de este planteamiento en Thirsk (1961) y Jones (1968). Sin salir de España, encontramos modelos similares en muchas comarcas septentrionales: Fernández de Pinedo (1974); Carmona (1990); Gallego Martínez, Germán y Pinilla (1992), y Dominguez Martín (1996). En otros lugares de Europa, Fontaine (1988) y Raggio (1991).

"En la que, a pesar de una pequeña desigualdad en el reparto de la tierra, predominaban los propietarios y el cultivo directo. Como en todas las montañas, altos costes, por las exigencias de trabajo, y cortos beneficios se aliaban para impedir una organización diferente; Coppola (1989), p. 500. La gratuidad del trabajo familiar y su bajo coste de oportunidad eran los únicos estímulos para obtener unos ingresos irrisorios, pero que ayu. daban a la subsistencia y otorgaban un mínimo de seguridad. 
La trashumancia era la mayor riqueza de la sierra gracias a los privilegios institucionales y al comercio de lana fina ${ }^{12}$. Constituía la base de una especialización ganadera adaptada a las condiciones geográficas y, en la práctica, significaba una transferencia de rentas de los pastizales extremeños y de los agostaderos comunales serranos hacia los bolsillos de los grandes ganaderos y las arcas de los exportadores de lana bilbaínos. La trashumancia era una gran empresa controlada por unos pocos grandes ganaderos ${ }^{13}$. Una clase poderosa económica y socialmente: en estas sierras, la clave del éxito de los propietarios de las cabañas residía en la reducción de costes, única vía para controlar la cuenta de resultados y asegurar el futuro de la explotación trashumante, y eso se lograba minimizando los costes laborales y dominando el acceso a los pastizales, tanto de verano como de invierno ${ }^{14}$.

A la vez, desde el punto de vista de los serranos, la ganadería trashumante alimentaba la demanda de trabajo y ofrecía abundantes ocasiones para la práctica de la pluriactividad ${ }^{15}$. La movilidad de los pastores, de modo indirecto, animaba la proliferación de pequeños negocios por las poblaciones cercanas a las cañadas. Las rutas del ganado ovino eran vías pecuarias, pero también canales de comunicación y un rico torrente de flujos económicos diversos. Por todas estas razones, no está fuera de lógica considerar a la trashumancia como una actividad monetizadora.

El textil admitía una pluralidad de formas de organización que no está bien recogida en las primeras versiones de la teoría de la protoindustrialización. Desde la ligadura entre la ciudad y el campo que provocaba la presencia de comerciantes urbanos, hasta la posibilidad de una comer-

12 Serían unas 440.000 cabezas de ganado merino, con una densidad que oscilaba entre las 177 y las 344 ovejas por kilómetro cuadrado en La Demanda y en Cameros. En Tierra de Soria, la densidad era de unas 100 cabezas, en San Pedro Manrique y Yanguas rondaba las 400; Pérez Romero (1996), p. 95.

${ }^{13}$ La concentración de la propiedad pecuaria en la trashumancia riojana, medida con el coeficiente de Gini, era elevadísima, de 0,87; a partir de los datos de Pérez Romero (1996), p. 101, en Tierra de Soria, el indice era muy similar, 0,81. Sólo los grandes propietarios podían mantener estas estrategias, lo que explica una constante desproporción entre las grandes cabañas y las pequeñas excusas de los pastores; Pérez Romero (1995) y (1998); García Sanz (1996).

${ }^{14}$ Así, el coste por cabeza de las hierbas de agostadero resultaba muy reducido. Otras empresas pecuarias, como las sostenidas por los grandes monasterios, como EI Paular o Guadalupe, soportaban mayores gastos en la alimentación del ganado pero eludían el pago del diezmo; Llopis (1982) y (1998).

is Con la carga ganadera existente, el número de pastores superaba los 2.000 , una demanda de trabajo muy importante para los 8.000 vecinos que residian en esta área. 
cialización difusa, acéfala y minifundista, es posible encontrar distintos modelos de organización del trabajo ${ }^{16}$. Su configuración concreta respondía a un conjunto de influencias de muy diversa genealogía: el tipo y la calidad de los textiles, los equilibrios sociales de las comunidades productoras, las alternativas económicas existentes, etcétera. Asimismo, los resultados demográficos, económicos y sociales de la protoindustria fueron diversos en distintas regiones, del mismo modo que la extensión de las artesanías rurales se produjo de forma particular y adaptada al medio socioeconómico local. En La Rioja, por ejemplo, convivían una extendida industria pañera de calidades comunes - paños y bayetas dieciseisenos, más algún veinteno- que era distribuida a pequeña escala por un elevado número de pequeños comerciantes que trajinaban con todo tipo de productos, y otra industria lanera especializada en calidades un poco superiores, localizada en uno o dos núcleos de población - Soto y la recién nacida Real Fábrica en Ezcaray-, con diferentes exigencias productivas y con una comercialización especializada que había generado una subclase de mercaderes de mediano tamaño, así como la aparición de algunas compañías de comercio con posibilidades de acumulación ${ }^{17}$. Ambas tenían orígenes comunes: la insuficiencia alimentaria, el bajo coste de oportunidad del trabajo y la disponibilidad de las fuentes de energía imprescindibles para alimentar los tintes y mover los batanes. Ambas se adaptaban al contexto social local y de mercado, dejándose influir por él y transformándolo. Ambas, por último, compartieron el mismo destino, aunque con cierto desfase temporal: la temprana crisis del textil barato se produjo a finales del xvir, y la desarticulación de los últimos empeños industriales llegó a partir de mediados del siglo XIX.

Pero si la estructura social que se desprende de la trashumancia era muy desigual, de las manufacturas se desgaja algo parecido a una clase media compuesta por unas pocas familias acomodadas que actuaban como soporte económico, proporcionando continuidad al textil y dando cierto

16 Varias muestras en Gullickson (1982), Hudson (1995) y Ogilvie y Cerman (1996). En España, Torras (1981) y García Sanz (1991). Como afirma Berg (1991), p. 191, en una discusión sobre la división del trabajo, los sistemas de putting-out, la fábrica y la innovación, no hay una superioridad intrínseca de un modelo sobre otro: «su relativa eficiencia depende del contexto económico».

17 Los trabajos en la industria textil producian sobre las 400.000 varas de paños anuales y, para ello, implicaban a unas 6.500 personas, con distintos grados de intensidad, en las distintas fases del proceso de elaboración. Se trataba, con mucho, de la principal dedicación en la sierra. Los fabricantes eran unas 1.700 personas, de las que el 92 por 100 se situaba por debajo de los diez paños anuales. Sólo el 1 por 100 de ellos superaba las 40 piezas con regularidad. 
equilibrio social a las localidades serranas. Eran los fabricantes medianos -en torno al 7 por 100 , entre 10 y 40 paños- quienes sostenían la actividad manteniendo un volumen de producción más o menos constante, aunque registraban oscilaciones en su actividad en función de las condiciones de la demanda, de la reserva de recursos y del suministro de materias primas. Los demás, sobre el 90 por 100 de los fabricantes, eran dueños de la materia prima y del producto acabado, pero seguían sólo una lógica pluriactiva: pocos paños, bruscas fluctuaciones en el tiempo, poca tierra, un poco de ganado estante, algunas ovejas trashumantes y algún trato ventajoso de vez en cuando. Si para ellos era posible esta pañería atomizada, la razón estaba en la especialización en las calidades comunes, con bajas exigencias de capital fijo, en las pulsiones naturales hacia la diversificación de riesgos aprovechando el excedente de mano de obra familiar, en la continuidad del negocio que aseguraban unas pocas familias y en la actividad de los comerciantes, que mantenían abiertos los canales de distribución ${ }^{18}$.

El comercio de paños serrano estaba también muy fragmentado. No tanto como la fábrica, porque, como es evidente, la distribución forzaba una escala mínima que desaconsejaba emprender el negocio a quien no la alcanzara. También porque, en teoría, la comercialización de los paños producía economías de aglomeración que invitaban a sus actores a ampliar las dimensiones del tráfico. Sin embargo, la escala eficiente, a juzgar por el tamaño más habitual, parecía reducirse a unas magnitudes intermedias, ni grandes ni demasiado pequeñas ${ }^{19}$. Las condiciones en que se desenvolvía el comercio de paños impedían un aumento en el volumen de comercialización de cada mercader: primero, la propia pluriactividad de los comer-

${ }^{18}$ El paño común tenía unos requisitos poco rigurosos respecto del grado de especialización de la mano de obra y del equipamiento en capital fijo. Gracias a ello era posible la intervención masiva de las familias serranas, poco especializadas y nada capitalizadas, en los procesos de transformación.

19 De todas formas, el número de comerciantes de paños era muy elevado. Oscilaba entre un comerciante cada dos fabricantes y uno cada cuatro o cinco: en Laguna había 67 comerciantes para 106 fabricantes; en Torrecilla, 79 para 108, y en Soto, 44 para 190. No hay por ello que juzgar imposible la actividad, porque los paños eran la excusa para salir de la sierra y comenzar a hacer tratos, pero no agotaban la actividad de los trajineros. Como atestiguan los protocolos notariales de los pueblos serranos, antes de volver a la sierra muchos de ellos habían comprado y vendido muchas mercancías diferentes a lo largo de sus rutas; estrategias similares se describen en Muset Pons (1995); Ringrose (1987) y Vassberg (1996). 
ciantes, forzada por sus reducidos recursos ${ }^{20}$; segundo, la especialización en bajas calidades, que facilitaba una distribución atomizada, y, tercero, la persistencia de los vínculos personales que en el marco mercantil precapitalista hacían prevalecer la confianza y el conocimiento mutuo, lo que, en este contexto, significaba que fabricante y comerciante solían compartir vecindad.

La familia permite entender cómo las bases económicas de la montaña se entrelazaban. En el sur de La Rioja, una familia con hijos varones podía recurrir a emplearlos' como pastores en las cabañas trashumantes, logrando por este medio una reducción de las necesidades de consumo del grupo familiar y adquiriendo una liquidez, en forma de salario en metálico, que permitía emprender aventuras económicas de baja capitalización en el terreno de las actividades de transformación o del transporte, al menos en los momentos o en los casos en los que el ciclo familiar, la dotación patrimonial inicial y las oportunidades de disfrute de la riqueza comunal les eran propicios ${ }^{21}$. Si, en vez de esto, se contaba con hijas, se disponía de mano de obra que podía ser empleada en la hilatura. Cuando los hijos eran demasiado pequeños, o en el momento de emancipación de la prole, sin embargo, se estaba en una situación menos halagüeña. Entonces el varón se empleaba como pastor $\mathrm{y}$, todo lo más, aprovechaba algunos tiempos muertos en la conducción y vigilancia del ganado para negociar con paños o con cualquier otra mercadería, mientras la mujer se encargaba de trabajar la poca tierra disponible y de hilar lana.

La pluriactividad, el comportamiento económico seguido en masa desde los hogares serranos, tenía dos condiçionantes: la composición de la fuerza de trabajo familiar y el abanico de las oportunidades a su alcance para obtener ingresos. La interacción entre los dos es evidente, pero a efectos analíticos podemos considerar al primero endógeno y al segundo hasta cierto punto exógeno, al menos desde un enfoque familiar ${ }^{22}$. El primer factor determinaba las opciones del grupo en función de la división sexual y generacional del trabajo. El segundo dependía de las condiciones naturales

${ }^{20}$ Muchos comerciantes se llevaban el paño a crédito, con el compromiso de pagarlo al fabricante en el momento de la vuelta. En los inventarios post mortem y en otros instrumentos notariales, no es raro encontrar ejemplos de ello, como en el concurso de acreedores formado al pequeño comerciante Manuel Moreno; AHPLR, Protocolos, Pedro Mar. tínez de Mateo, 1754, caja 8.503, f. 95.

${ }^{21}$ Moreno Fernández (2000).

${ }^{22}$ Aunque desde luego no lo era tanto en la medida en que el acceso a la riqueza ambiental común y al mercado eran resultado de los equilibrios sociales, de los mecanismos de negociación social y de la organización institucional local. 
tanto como de las posibilidades de mercado. Este último rasgo del modelo no lo convertía en una organización estable por sí misma ${ }^{23}$. Su viabilidad dependía del estado del mercado, para dar salida a los productos serranos en un plano internacional en el caso de la lana merina, nacional en el caso de los paños, y para lograr el abastecimiento regular de los productos deficitarios, vino y alimentos sobre todo. Como siempre que el mercado rondaba cerca, había continuas distorsiones. El desequilibrio era lo único seguro. De ahí que la autorregulación institucional llevada a cabo por los concejos no fuera estática.

La primera exigencia en una economía penetrada por el mercado era la flexibilidad, la capacidad de adaptación a las alteraciones que no dejaban de producirse. Para lograrla se seguía una máxima común al conjunto de la sociedad precapitalista: la vigilancia sobre los mercados para dominar su capacidad de producir transformaciones ${ }^{24}$. Dicho de otro modo, el mercado - entendido como un mecanismo de coordinación económica que orienta decisiones productivas- estaba presente, pero el mercado no regía la sociedad, sino que era controlado por ella. Había diversos mecanismos dirigidos a la reducción de las asimetrías, a la aminoración de la incertidumbre y al control del riesgo. Construyendo vínculos clientelares se disimulaba la dominación de los poderosos y, a veces de forma duradera, se exorcizaban las consecuencias más temidas de las asimetrías. Despojando a los mercados de anonimato y basando las relaciones mercantiles en la confianza se mantenían algunos riesgos a raya ${ }^{25}$. Al mismo tiempo, mediante la defensa de organizaciones estabilizadoras - pósitos, arcas de misericordia - y gracias a la profusión de privilegios y trabas característicos del proteccionismo mercantilista, se intentaba disminuir la incertidumbre. Se trataba de estrategias cautelosas, flexibles y cambiantes que afectaban

${ }^{23}$ Sobre la discusión acerca de la estabilidad y el cambio de las zonas españolas afectadas por la movilidad de la población se pueden ver las medidas conclusiones de Vassberg (1996), pp. 174-175.

${ }^{24}$ Como afirmaba Polanyi [(1944) 1989], p. 121, hasta el siglo xx, «los mercados han sido únicamente elementos secundarios de la vida económica», o, lo que es casi lo mismo, pero con más precisión, «el sistema económico estaba integrado en el sistema social».

${ }^{25}$ Aunque eso exigiera una renuncia tácita de todos los agentes a mantener un comportamiento oportunista. En cualquier caso, el comportamiento oportunista no es la norma de actuación social en todo momento y en toda circunstancia. Algunas críticas a la concepción ahistórica del homo oeconomicus, contraponiéndola a la idea del «individuo en relación con las instituciones», se pueden ver en Hodgson (1995). Una visión sobre el pensamiento económico preindustrial, más moral que maximizador, en García Sanz (1999). 
a los comportamientos privados y al diseño institucional de las organizaciones del poder local ${ }^{26}$.

Hoy ya es una idea aceptada que el mercado en el Antiguo Régimen era cualquier cosa menos anónimo. Sin embargo, otros de sus rasgos están insuficientemente analizados, por lo que será útil ahondar en algunas ideas acerca del comportamiento de los mercados precapitalistas. Con una precisión para empezar: en este contexto, para sustituir la terminología de las «perfecciones» o las «definiciones de derechos de propiedad», A. Bhaduri propone el concepto de «eficiencia de clase», una herramienta útil para comprender algunas reglas formales e informales que regulan el funcionamiento de las instituciones económicas, y entre ellas el mercado. La norma para explicar los mecanismos reales que rigen el comportamiento del mercado no será, según él, la eficiencia productiva al modo del óptimo de Pareto, sino los beneficios que sea capaz de obtener la clase dominante ${ }^{27}$. Dicho así, tal vez suene demasiado fuerte, porque como ha indicado Gallego, la capacidad de durar de una organización social no se puede basar tan sólo en la capacidad de acumulación de una clase, aunque para todos sea evidente que la clase dominante tiene una superior capacidad de maniobra a la hora de dirigir los aspectos normativos de las instituciones ${ }^{28}$. Pero la mera imposición raras veces funciona. Si un sistema busca un mínimo de estabilidad - una necesidad para el desarrollo-, debe demostrar su capacidad para encajar los intereses de clase con la negociación social y con los entramados ambiental, técnico e institucional. Sin embargo, el concepto de Bhaduri es apropiado, usado con prudencia y complementado con el concepto «racionalidad de clase» frente a la extendida imagen de una racionalidad común a todos los individuos.

Dicho esto hay que precisar que las imperfecciones del mercado eran de muy diversa índole, pero, sobre todo, había dos conjuntos de problemas entrelazados que provocaban comportamientos peculiares en la relación de los agentes económicos con el mercado. En primer lugar, hay que contar con las asimetrías, en muchas ocasiones incluso sancionadas políticamente. Éste es el aspecto al que mejor se ajusta el concepto de eficiencia de clase de Bhaduri. El intercambio de productos estaba alterado por pri-

${ }^{26}$ Formalmente, los controles para reducir riesgos se manifestaban en las regulaciones concejiles, Moreno Fernández (1998); informalmente, en la proliferación de limitaciones espontáneas improvisadas por los agentes. En el fondo, era una economía moral al modo de Thompson (1995).

27 Bhaduri (1991) y (1998).

${ }^{28}$ Gallego Martínez (1998) preferiría ampliarlo a las «eficiencias de clase», como modo de devolver a los débiles su papel activo en tanto que agentes sociales. 
vilegios, restricciones y una tupida red de pequeños, o no tan pequeños, mercados cautivos. Para unos, el modo de extraer beneficios de la situación consistía en explotar mecanismos especulativos. Para otros no había caso: estaban tan desesperados por su posición económica que participaban en el mercado a impulsos del hambre, un medio seguro para ser víctima de todo género de abusos. Algo parecido sucedía en los mercados de factores, sólo que en éstos el modo de sacar provecho era el control de las instancias de poder que se ocupaban de su regulación. Al fin, la acumulación era para los poderosos un camino conectado al poder y a las artimañas mercantiles. Todo lo contrario de cualquier noción técnica de eficiencia productiva o comercial, que no les preocupaba gran cosa porque no les hacía ninguna falta. Ahora bien, a partir de aquí vienen los matices: también el control de los poderosos tenía límites. El logro de sus objetivos no era un simple fruto de la prepotencia, también tenía una pequeña dosis de transacción en algunos puntos esenciales. Las eficiencias de clase de la autorregulación concejil incluían objetivos sociales para garantizar un contexto de estabilidad en el que desenvolver con seguridad las actividades productivas.

El segundo conjunto de problemas venía por el lado de la incertidumbre, ligada a la falta de desarrollo técnico y a la convivencia de derechos de propiedad variables según las comarcas o los entornos locales. La incertidumbre afectaba sobre todo al mundo de la distribución, pero también tocaba a la producción y a las finanzas. El resultado principal consistía en que generaba comportamientos medrosos, poco emprendedores. Limitaba la expansión de los negocios y frenaba la capacidad de innovar. La costumbre de diversificar inversiones y de practicar al mismo tiempo negocios distintos, por ejemplo, se extendia entre los grandes y los pequeños y para todos tenía detrás la misma lógica: la aversión al riesgo. Sólo que esta aversión al riesgo no era una enfermedad, un sarampión pasajero de empresas o sociedades infantiles que cuando maduraran dejarian de comportarse de modo poco racional. Era mucho más que eso. El riesgo era algo presente, tangible y cotidiano. Los comportamientos temerarios podían dar al traste con una empresa de servicios comerciales del mismo modo que podían desmantelar, en un abrir y cerrar de ojos, una microempresa familiar campesina. No tener esto en cuenta podía significar la desaparición, tanto de la empresa comercial como del hogar campesino. Con la ligera diferencia, no obstante, de que en el primer caso desaparecía una organización y en el segundo podian desaparecer personas. Así pues, la costumbre de reducir el riesgo por todos los medios era un resultado de las 
condiciones de este mercado privilegiado, imperfecto y con reglas muy precisas para seguir el camino de la supervivencia. Lo que, dicho rápido, no significa sino algo bastante conocido: la estructura social, que reposaba sobre la desigualdad, establecía las reglas del juego a las que se atenían el mercado y las demás instituciones. Al fin, en la sociedad preindustrial, el mercado era el adjetivo, y la estructura social, el sustantivo. Y eso implica que las reglas del mercado variaban en función de la historicidad de la estructura social, igualmente cambiante. Dicho de otro modo, lo que hay que analizar es cómo el mercado ha seguido leyes diferentes en sociedades y épocas distintas, a partir de los modos en que evolucionan de forma conjunta la sociedad, el marco institucional y la economía.

La complejidad económica se resolvía, desde el punto de vista de la organización de la producción y del trabajo, en el desarrollo de mecanismos asimismo complejos, establecidos y defendidos a la vez desde arriba y desde abajo. El comunal, la familia, el control social ganadero, la dotación patrimonial de cada uno y la atomización productiva de la pañería, por ejemplo, no eran más que algunos de los factores que influían en una organización del trabajo tan mediatizada por el mercado como por el panorama familiar ${ }^{29}$. El comunal no era sólo disponer de montes y pastos. También se nutría de un componente institucional: el colectivismo. Se manifestaba en un control obsesivo de las bases económicas, una vigilancia estrecha de los precios y los salarios, la supervisión constante de la organización del trabajo, la regulación precisa de la vida pública y la injerencia permanente incluso en esferas de la vida privada. Ya es un tópico señalar el papel que los usos comunales desempeñaron a la hora de ordenar los abastos públicos, el mercado de trabajo, el calendario agrario, el tipo y los métodos de cultivo, etcétera. No eran temas intrascendentes. La vida en las comunidades rurales, más todavía en los pequeños pueblos de montaña, estaba encuadrada y sometida al marco familiar y al marco comunitario. El uno y el otro eran a la vez trampolín y prisión, el soporte de una identidad compartida que proporcionaba a los individuos sentimientos de pertenencia sólidos y el impedimento mayor para escapar a ellos. Un intervencionismo extremo manifestado a través de ordenanzas, bandos, costumbres, prácticas y normas informales que se proponía hacer valer las necesidades locales frente a cualquier injerencia exterior, fuera de origen legal o de mercado, y que aquí se ha denominado autorregulación.

En este escenario, el ejemplo del modo en que se organizaban los pastos concejiles puede resultar ilustrativo. La función económica de los

\footnotetext{
${ }^{29}$ Sobre el engarce entre mercado de trabajo y prácticas sociales, Grantham (1999).
} 
espacios de uso común iba de la mano de su importancia social. Vitales eran para los serranos modestos cuya propiedad ganadera, generalizada y reducida, les proporcionaba pequeños ingresos, así como la imprescindible fuerza de tracción para el cultivo de sus pegujales. De los concejiles obtenían también carbón, leña, caza y frutos que apuntalaban todavía más su subsistencia, sirviendo incluso en ocasiones para ejercer una pequeña actividad remunerada. Siempre pequeña, porque el acaparamiento de los recursos por parte de los ganaderos era tan evidente que los vecinos no podían aprovecharlos como un recurso para evitar el mercado de trabajo ${ }^{30}$. Sin embargo, tampoco la prepotencia ganadera era ilimitada. A fin de cuentas, en los pueblos más ricos en rebaños trashumantes, quienes debían salir de sus jurisdicciones a buscar pastos de agostadero, pagando por ellos, eran los ganaderos. Más aún, muchos de los arrendamientos de pastos, tenían que sufrir la carga explícita de permitir el apacentamiento de los ganados vecinales ${ }^{31}$. Así, el pastizal comunal tenía una lógica doble: facilitaba la acumulación de los poderosos, pero también la subsistencia de los pobres ${ }^{32}$. Lo que se traducía en una evidente lógica social: la reproducción.

\section{DE LA PROSPERIDAD A LA CRISIS}

De acuerdo con las condiciones ambientales, institucionales y con la propia trayectoria histórica, se habían ido configurando modelos diferentes en los que el dinamismo económico, sin embargo, era la norma. En las

${ }^{30}$ El reverso de la situación lo demuestra: en Castroviejo y Pazuengos, situados en la línea de contacto entre el valle y la sierra, alli donde la trashumancia no llegaba y donde no se experimentaba el poder de los ganaderos, la alternativa económica encontrada por los vecinos se basaba en otras formas de explotación de los patrimonios comunales. Leñadores y carboneros ocupaban el lugar de pastores, hilanderas y tejedores porque la estructura social y los pilares económicos eran distintos.

${ }^{31}$ En otras comarcas el encaje de las variables en torno a la trashumancia era diferente. En Tierra de Soria, por ejemplo, los ganaderos residían en la capital y aprovechaban los pastos vecinales gracias a la comunidad de pastos de toda la Tierra, pero había una evidente presión hacia la particularización del uso de los mejores pastos, las rastrojeras, a través de arrendamientos; Pérez Romero (1995), pp. 196-211, y (1996), pp. 96-100. En La Rioja, sin embargo, los derechos de uso sobre el comunal se vinculaban a la residencia en la propia localidad, y los ganaderos trashumantes, obligados a convivir con sus pastores, debían reducir la competencia potenciando redes clientelares, es decir, mecanismos de negociación que ampliaban el margen de los más pobres.

32 En cualquier caso, su eficiencia queda fuera de toda duda en el contexto mercantil preindustrial, algo que se está reconociendo ya en otras historiografías. 
montañas de la cornisa cantábrica, la mayor humedad multiplicaba los recursos pascícolas, la temprana introducción del maíz había liberado a la agricultura de la tiranía de los cereales tradicionales, y la protoindustria del hierro ofrecía alternativas remuneradoras y con cierto futuro. En montañas más secas y menos ricas en recursos energéticos y minerales, aunque se hubieran desplegado estrategias dinamizadoras en el siglo XVIII, el futuro se presentaba más sombrío. Ahora bien, tampoco todas las sierras eran enclaves dinámicos y la comparación con otras comarcas menos afortunadas puede resultar esclarecedora. Dos factores relevantes sirven para diferenciar, por ejemplo, las sierras riojanas de las sorianas: en aquéllas, el control de los recursos comunes era local, así como la vecindad de las oligarquías; en Soria, un poderoso grupo de terratenientes y linajudos ganaderos controlaba los pastizales desde la ciudad ${ }^{33}$. Esto pudo ser el origen de una mayor debilidad de los canales de negociación entre clases sociales, la clave que definía tanto las opciones de supervivencia como las de acumulación. Así, Pérez Romero encuentra en Soria una densa conflictividad social, pero en La Rioja parece haber una estabilidad general que sólo se rompe con la disgregación del modelo, ya hacia finales del siglo xviI. Estos factores desempeñarian un papel fundamental en el paso hacia una economía capitalista. En el modelo establecido a finales de la Edad Moderna se encerraban las capacidades y los límites de una adaptación a los cambios decimonónicos, que siempre sería complicada pero que se saldó con resultados muy variados, desde el éxito en el País Vasco marítimo hasta la desarticulación más rotunda en las montañas interiores del norte de Castilla o del sur de Aragón ${ }^{34}$.

La propia dinámica del crecimiento precapitalista impuso algunos cambios en el último tercio del siglo xviI. La indeterminación a la que estaban sujetas las economías dependientes del mercado se acentuó conforme el crecimiento iba alcanzando sus límites. La extensión de los cultivos y la elevación de la renta presionaban por doquier sobre el recurso tierra, provocando la disolución de los viejos privilegios trashumantes; al mismo tiempo, la subida de los precios y la práctica congelación de los salarios ero-

${ }^{33}$ La comparación tiene sus límites porque los sexmos montañosos tenían una densidad de población mayor que los agrícolas, lo que también sugiere cierto dinamismo; Pérez Romero (1995), pp. 29-37.

${ }^{34}$ Instituciones como la hidalguía universal, la baja señorialización de la zona, el régimen de heredero único, o la originalidad fiscal de las Provincias exentas que las convertía en economías de frontera, también determinaban las posibilidades de reproducción campesina y la creación de una plataforma más apta o menos para adaptarse al capitalismo. 
sionaban la demanda popular de paños de baja calidad, que tenían, además, que sufrir la competencia del recién llegado algodón ${ }^{35}$. Con la trashumancia y el textil disperso tambaleándose, la guerra de la Independencia aún vino a agravar las cosas y, un tiempo después, la ruptura con las bases institucionales del Antiguo Régimen alteró el escenario de forma irreversible.

Entre sus efectos más importantes, la liberalización económica se acompañó por una mayor penetración del mercado, por un aumento de la competencia y por una incipiente división regional, cuando no comarcal, del trabajo. En el nuevo contexto, las viejas virtudes de la montaña - la capacidad para negociar y la vitalidad de las producciones pecuaria e industrial, dirigidas al mercado- se extendían, los privilegios sobre los que se habían apoyado se evaporaban y, progresivamente, iban quedando al descubierto las desventajas competitivas de las áreas peor comunicadas y con menores dotaciones de recursos. Habían resultado eficaces en un contexto económico tradicional y sufrieron un impacto muy negativo con la ampliación de los mercados, que evidenció sus escasas posibilidades en un marco competitivo al mismo tiempo que aumentaba el atractivo de las áreas de reciente industrialización, que mejoraban su relación renta-población y atraían a la gente de áreas rurales más pobres ${ }^{36}$.

Como en todos los lugares, en La Rioja el proceso avanzó a trompicones y tuvo rasgos originales en un clima de cambio común. Comenzó con una reducción de las cabañas trashumantes desde los años sesenta del siglo XVIII, se complementó con la práctica desaparición del textil disperso hacia finales de siglo; empeoró durante la guerra de Independencia; se hizo inaguantable con la caída de las cotizaciones laneras a partir de los años veinte; se atenuó un poco con la nueva creación de algunas fábricas laneras concentradas y levemente mecanizadas alrededor de los cuarenta y cincuenta, y concluyó con el fracaso de éstas en la segunda mitad del siglo XIX. Entretanto, los poderosos trasladaban su residencia a Extremadura o a Madrid, y los menos resignados - los mejor equipados para encontrar oportunidades- emigraban a cualquier sitio: Galicia, Asturias, Cataluña, Andalucía, Extremadura o Madrid. El drenaje de capital, agravado por la fuga del capital humano, selló la sentencia para las sierras: marginalidad y, conforme

${ }^{35}$ Para las explicaciones clásicas sobre la crisis de la trashumancia, García Sanz (1978) y (1985) y Llopis Agelán (1982). Sobre salarios reales, Reher y Ballesteros (1993).

${ }^{36}$ Hay estudiados muchos otros casos: para el conjunto del valle del Ebro, Gallego, Germán y Pinilla (1992); para Aragón, Pinilla (1995); para Cantabria, Domínguez Martín (1995). Sobre el entorno global de las montañas del Mediterráneo, McNeill (1992), pp. 223-236. 
las últimas iniciativas fueran fracasando, despoblación. En todo caso, es crucial darse cuenta de que la crisis fue de las comarcas de la montaña, no de los montañeses. Aquellos que habían mostrado un mayor dinamismo, continuaron en vanguardia, aprovechando las oportunidades que planteaban las transformaciones institucionales. Ahora bien, para ello tuvieron que abandonar las sierras, situándose a partir de finales del siglo xvu y durante el primer tercio del XIX en áreas mejor localizadas desde el punto de vista económico ${ }^{37}$.

\section{CONCLUSIONES}

Primero un corolario metodológico. La historia local, por lo que tiene de microhistoria, cuando parte de presupuestos y modelos teóricos, es un buen método de análisis histórico. Desde abajo es posible superar las generalizaciones en beneficio de la pluralidad de enfoques y disciplinas ${ }^{38}$. Más aún, si se es sensible a las sugerencias de la documentación también es factible la exploración de interacciones imprevistas entre los niveles ambiental, económico, social e institucional, con el resultado final de que se pueden plantear nuevas preguntas capaces de enriquecer los modelos. En cualquier caso, aquí se defiende la importancia de mezclar las cosas, de observar las influencias recíprocas entre lo económico y lo social, atendiendo a las condiciones naturales y de mercado, y sin descuidar la organización institucional en la que tienen lugar las interacciones.

Con respecto a la valoración de los modos de organización tardofeudales, también cabe hacer una precisión: los criterios de eficiencia manejados por la economía neoclásica están pensados para sociedades de mercado capitalistas. No son válidos para contextos preindustriales en los que las instituciones y los objetivos sociales eran diferentes. Si queremos comprender los modelos de organización social precapitalistas, hay que valorar su eficiencia con arreglo a su propia lógica interna, con el uso de los criterios que se desprenden de su propio contexto social, económico e institucional.

En lo referente a la montaña parece necesario modificar la óptica pesimista con la que se ha tendido a enfocar, o mejor a eludir, su análisis.

${ }^{37}$ Es larga la lista de serranos emprendedores que triunfaron en el comercio de Cádiz, en la siderurgia andaluza, en el comercio y la industria gallegos o en las finanzas extremeñas. Otras diásporas mercantiles, como la catalana, han sido estudiadas por Torras (1995) y Lluch (1999), pp. 93-115.

38 Woolf (1991), pp. 10-11. 
Fue también en algunas zonas poco aptas para el cultivo agrícola donde, cuando las condiciones sociales lo hicieron posible, se desarrolló el germen del capitalismo. No sólo la ciudad se comportó como un enclave dinámico, capitalista y creativo. Los montañeses eran, por lo menos a mediados del siglo XVII, mucho más que destripaterrones. Siempre que hubo ocasión, algunos serranos de La Rioja demostraron que sabían manejarse en el proceloso mundo del mercado y sacar partido a sus habilidades. Para ellos, después de años de aprendizaje, la montaña se había convertido en una suerte de escuela de comercio natural donde se difundía el talento mercantil, se asimilaban destrezas para el cálculo, se pulía la soltura en la negociación, se fomentaba el sondeo de nuevas oportunidades y se inoculaban, en suma, hábitos capitalistas. Esta circunstancia dotaba a las zonas no agrícolas de una ventaja, su abundancia en capital humano, para competir en el flamante entorno, más o menos regido por el mercado, que se desarrolló a partir de las décadas finales del siglo Xvir. Aunque no sólo de capital humano se ha forjado el crecimiento económico. También eran imprescindibles otros recursos y aquí es donde la montaña jugó con desventaja y se reveló incapaz de aprovechar sus oportunidades. Además, el capital humano, a diferencia de los recursos naturales, la localización o algunos tipos de capital físico, se podía trasladar con facilidad. Bastaba una emigración selectiva, la de los más espabilados, para despojar a las montañas de su más brillante cualidad.

De lo anterior se concluye la necesidad de realizar una profunda revisión acerca de nuestras ideas sobre la economía preindustrial. La abundancia en el uso del término subsistencia, que en sus versiones más extremas se presenta como simple autarquía, impide percibir los grandes cambios, inducidos por el mercado, que se habían producido a la altura de mediados del siglo xvil en extensas áreas de la península. Y son estos cambios previos los que socavaron los cimientos del Antiguo Régimen, facilitando su desmoronamiento, aunque el edificio se mantuviera en estado de ruina durante varias décadas.

\section{BIBLIOGRAFÍA}

ACín, J. L., y Pinilla, V. (coords.) (1995): Pueblos abandonados. ¿Un mundo perdido?, Zaragoza, Rolde.

Berg, M. (1991): «On the Origins of Capitalist Hierarchy», en B. Gustafsson (ed.), Power and Economic Institutions. Reinterpretations in Economic History, Hants, Edward Elgar, pp. 173-194. 
Bhaduri, A. (1991): «Economic Power and Productive Efficiency in Traditional Agriculture», en B. Gustafsson (ed.), Power and Economic Institutions. Reinterpretations in Economic History, Hants, Edward Elgar, pp. 53-68.

BHADURT, A. (1998): «Eficiencia económica e instituciones agrarias», Historia Agraria, 15 , pp. 15-25.

Carmona Badia, X. (1990): El atraso industrial de Galicia. Auge y liquidación de las manufacturas textiles (1750-1900), Barcelona, Ariel.

CAzzol.A, F. (1987): «La pluriativitá nelle campagne italiane: alcuni problemi interpretativi», Bolletino Bibliografico del Centro Studi per la Storia, 38, pp. 877-913.

Coppola, G. (1989): «La montagna alpina. Vocazioni originarie e trasformazioni funzionali», en P. BevilacQua (ed.), Storia dell'agricoltura italiana in età contemporanea. I. Spazi e paesaggi, Venecia, Marsilio, pp. 495-530.

Domínguez Martín, R. (1992): «Campesinos, mercado y adaptación. Una propuesta de síntesis e interpretación desde una perspectiva interdisciplinar», Noticiario de Historia Agraria, 3, pp. 91-130.

- (1993): «Caracterizando al campesinado y a la economía campesina: pluriactividad y dependencia del mercado como nuevos atributos de la campesinidad», Agricultura y Sociedad, 66, pp. 97-136.

- (1995): «De reserva demográfica a reserva etnográfica: el declive de las economías de montaña en el área cantábrica», en J. L. Acín y V. Pinilla (coords.), Pueblos abandonados. ¿Un mundo perdido?, Zaragoza, Rolde, pp. 35-54.

- (1996): El campesinado adaptativo. Campesinos y mercado en el Norte de España, 1750-1880, Santander, Universidad de Cantabria.

FERNÁNDEZ DE PINEDO, E. (1974): Crecimiento económico y transformaciones sociales del País Vasco (1500-1850), Madrid, Siglo XXI.

FonTAINE, L. (1988): «Le reti del credito, la montagna, la città, la pianura: mercanti dell'Oisans tra XVII e XIX secolo», Quaderni Storici, núm. 68, pp. 573-593.

- (1991): «Family Cycles, Peddling and Society in Upper Alpine Valleys in the Eighteenth Century», en S. WoOLF (ed.), Domestic Strategies: Work and Family in France and Italy. 1600-1800, Cambridge, Cambridge University, pp. 43-68.

GALLEGO MARTínEZ, D. (1998): «De la sociedad rural en la España contemporánea y del concepto de sociedad capitalista: un ensayo", Historia Agraria, 16, pp. 13-53.

Gallego Martinez, D.; Germán Zubero, L., y Pinilla Navarro, V. (1992): «Transformaciones económicas en el Valle del Ebro (1800-1936)», en J. M. SERRANo (dir.), Estructuras económicas del Valle del Ebro, Madrid, Espasa Calpe, pp. 129-166.

Garcia Ruiz, J. M. (1990): «El viejo dilema: estabilidad e inestabilidad de los ecosistemas de montaña», en Geoecología de las áreas de montaña, Logroño, Geoforma, pp. 313.337.

García SAnZ, A. (1978): «La agonía de la Mesta y el hundimiento de las exportaciones laneras: un capítulo de la crisis económica del Antiguo Régimen en España», Agricultura y Sociedad, 6, pp. 283-316.

- (1985): «Algo más sobre el final de la Mesta y la crisis de la trashumancia: a propósito de la publicación de un "Tratado práctico de ganadería merina" escrito en 1826», Agricultura y Sociedad, 34, pp. 275-338. 
- (1991): «Organización productiva y relaciones contractuales en la pañeria segoviana en el siglo XVI», en M. BARCELÓ CRESPi (ed.), IX Jornades d'Estudis Historics Locals. La manufactura urbana i els menestrals (ss. XIII-XVI), Palma de Mallorca, Institut d'Estudis Baleàrics, pp. 177-192.

- (1996): «Empresarios en la España del Antiguo Régimen: ganaderos trashumantes, exportadores de lana y fabricantes de paños», en F. COMín y P. MARTín ACEN̂A (eds.), La empresa en la bistoria de España, Madrid, Civitas, pp. 93-113.

- (1999): «El contexto económico del pensamiento escolástico: el florecimiento del capital mercantil en la España del siglo xvı, en E. Fuentes QuinTANA (dir.), Economía y economistas españoles. 2. De los origenes al mercantilismo, Barcelona, Galaxia Gutenberg, pp. 131-162.

Garrier, G., y HubScher, R. (eds.) (1988): Entre faucilles et marteaux. Pluriactivités et stratégies paysannes, Lyon, Presses Universitaires de Lyon.

Garrier, G.; Goujon, P., y Rinaudo, Y. (1988): «Annexe: note d'orientation et de recherche», en G. GARRIER y R. HUBSCHER (eds.), Entre faucilles et marteaux. Pluriactivités et stratégies paysannes, Lyon, Presses Universitaires de Lyon, pp. 233-237.

Grantham, G. (1999): «The Evolution of Agricultural Labour Market», trabajo presentado en el IX Congreso de Historia Agraria, Bilbao.

Gullickson, G. L. (1982): «Proto-industrialization, demographic behaviour and the sexual division of labour in Auffay, France», Peasant Studies, 9, pp. 105-118.

GuSTAFSSON, B. (ed.) (1991): Power and Economic Institutions. Reinterpretations in Economic History, Hants, Edward Elgar.

Hodgson, G. M. (1995): Economia y evolución. Revitalizando la economia, Madrid, Celeste.

HudSON, P. (1995): «La tenencia de tierras y la organización de la manufactura textil en las poblaciones rurales de Yorkshire c. 1660-1810», en M. BERG (ed.), Mercados y manufacturas en Europa, Barcelona, Crítica, pp. 210-246.

Jones, E. L. (1968): «Agricultural Origins of Industry», Past and Present, 40, pp. $58-71$.

Lanza García, R. (1988): Población y familia campesina en el Antiguo Régimen. Liébana, ss. XVI-XIX, Santander.

LLOPIS AGELÁN, E. (1982): «Las explotaciones trashumantes en el siglo XvIII y primer tercio del xax: la cabaña del Monasterio de Guadalupe, 1709-1835», en G. ANes (ed.), La economía española al final del Antiguo Régimen. I. Agricultura, Madrid, Alianza, pp. 1-101.

- (1998): «Medio siglo de una gran explotación trashumante: la cabaña merina del monasterio de El Paular, 1680-1730», en F. Ruiz Martín y A. García SANZ (eds.), Mesta, trashumancia y lana en la España moderna, Barcelona, Crítica, pp. 144-197.

LlUCH, E. (1999): Las Españas vencidas del siglo XVIII, Barcelona, Crítica.

MaYaud, J. L. (1988): «De l'étable à l'établi: permanence des adaptations dans la montagne jurassienne», en G. GARRIER y R. HUBSCHER (eds.), Entre faucilles et marteaux. Pluriactivités et stratégies paysannes, Lyon, Presses Universitaires de Lyon, pp. 143.159.

McNeil., J. R. (1992): The Mountains of the Mediterranean World. An Environmental History, Cambridge, Cambridge University Press. 
Moreno Fernández, J. R. (1998): «El régimen comunal y la reproducción de la comunidad campesina en las sierras de La Rioja, siglos XvIII-XIX», Historia Agraria, 15, pp. 75-111.

- (1999): «La economía de montaña en La Rioja a mediados del siglo xvII», tesis doctoral, Universidad de Zaragoza.

- (2000): «Entre el padre y el patrón. La organización del trabajo trashumante en la montaña riojana (s. XVIII)», Historia Agraria, 22, pp. 131-158.

MUSET PONS, A. (1995): «Los arrieros y negociantes de Calaf y Copons y su implantación en el mercado español en el siglo XVIn», Revista de Historia Industrial, 8, pp. 193-208.

OgILVIE, S. C., y Cerman, M. (eds.) (1996): European proto-industrialization, Cambridge, Cambridge University Press.

ORTEGa VALCÁRCEL, J. (1974): La transformación de un espacio rural: las montañas de Burgos, Valladolid, Universidad de Valladolid.

Pérez Romero, E. (1995): Patrimonios comunales, ganadería trashumante y sociedad en la Tierra de Soria. Siglos XVIII-XIX, Salamanca, Junta de Castilla y León.

- (1996): «Trashumancia y pastos de agostadero en las sierras sorianas durante el siglo xvய», Revista de Historia Económica, 14, 1, pp. 91-124.

- (1998): «La trashumancia y sus repercusiones económicas y sociales en zonas de agostadero: el caso de la Tierra de Soria en el siglo XVII»), en F. Ruiz Martín y A. García SANZ (eds.), Mesta, trashumancia y lana en la España moderna, Barcelona, Crítica, pp. 198-230.

Pinilla Navarro, V. (1995): «Crisis, declive y adaptación de las economías de montaña: una interpretación sobre la despoblación en Aragón», en J. L. Acín, y V. Pinilla (coords.), Pueblos abandonados. ¿Un mundo perdido?, Zaragoza, Rolde, pp. 55-78.

PolANYI, K. [(1944) 1989]: La gran transformación. Crítica del liberalismo económico, Madrid, La Piqueta.

RAGGIO, O. (1991): «Social relations and control of resources in an area of transit: eastern Liguria, sixteenth to seventeenth centuries», en S. WoOlF (ed.), Domestic Strategies: Work and Family in France and Italy. 1600-1800, Cambridge, Cambridge University Press, pp. 20-42.

Reher, D. S., y Ballesteros, E. (1993): «Precios y salarios en Castilla la Nueva: la construcción de un índice de salarios reales, 1501-1991», Revista de Historia Económica, 11, 1, pp. 101-151.

Ringrose, D. R. (1987): Imperio y Peninsula. Ensayos sobre bistoria económica de España (siglos XVI-XIX), Madrid, Siglo XXI.

Ruiz Martin, F., y Garcia SAnz, A. (eds.) (1998): Mesta, trashumancia y lana en la España moderna, Barcelona, Crítica.

SARASÚA, C. (1994): «Las migraciones temporales en una economía de minifundio: los montes del Pas, 1758-1888», Boletin de la Asociación de Demografia Histórica, 12, 2-3, pp. 165-179.

ThIRSK, J. (1961): «Industries in the Countryside», en F. J. Fisher (ed.), Essays in the Economic and Social History of Tudor and Stuart England in Honour of $R$ J. Tawney, Cambridge, Cambridge University Press, pp. 70-88.

Tiłompson, E. P. (1995): Costumbres en común, Barcelona, Crítica. 
TORRAS, J. (1981): «Estructura de la indústria pre-capitalista: la draperia», Recerques, 11, pp. 7-28.

- (1995): «Redes comerciales y auge textil en la España del siglo xviI», en M. Berg (ed.), Mercados y manufacturas en Europa, Barcelona, Crítica, pp. 111-132.

VASSBERG, D. E. (1996): The Village and the Outside World in Golden Age Castille. Mobility and Migration in Everyday Rural Life, Cambridge, Cambridge University Press.

WOOLF, S. (1991): «Introduction. Domestic strategies: work and family in France and Italy. 1600-1800», en S. WOOLF (ed.), Domestic Strategies: Work and Family in France and Italy. 1600-1800, Cambridge, Cambridge University Press, pp. 1-19. 